\title{
REGULATION OF MACROPHAGE TUMOR NECROSIS FACTOR PRODUCTION BY PROSTAGLANDIN $E_{2}$
}

S.L. Kunke1, R.C. Wiggins, S.W. Chensue, and J. Larrick*

Departments of Pathology and Internal Medicine University of Michigan Medical School

Ann Arbor, MI 48109

*Cetus Immune Corporation, Palo Alto, California 94303

Received April 11, 1986

We have studied the role of prostaglandin $E_{2}$ on the modulation of tumor necrosis factor by immunologically elicited and lipopolysaccharide treated murine macrophages. Indomethacin, a potent inhibitor of prostaglandin $E_{2}$ production, caused a dose dependent augmentation of fipopolysaccharide induced tumor necrosis factor production $\left(2-3\right.$ fold at $10^{-7}$ molar $)$. Tumor necrosis factor was released into the extracellular environment and no activity was found to be associated with membrane or cytosolic fractions. Prostaglandin $E_{2}$ added to the lipopolysaccharide treated cultures suppressed tumor necrosis factor in a dose dependent manner. In these studies, $10^{-7}$ molar PGE reduced tumor necrosis factor production to basal levels. These data suggest that $\mathrm{PGE}_{2}$ may be a potent autoregulatory factor that dramatically influences tumor necrosis factor production. 1986 Academic Press, Inc.

Macrophage-derived tumor necrosis factor (TNF) ${ }^{\star \star}$ is being increasingly recognized as an important monokine effecting a variety of target cells in diverse ways. Although tumor cells were the original targets as defined by Carswell et al. (1), it is no longer accurate to regard TNF solely as an oncolytic agent. Current evidence demonstrates that TNF may stimulate a variety of cellular responses. For example, TNF has been identified as a macrophage product that: a) binds to high affinity receptors present on adipocytes (2) and suppresses the production of lipoprotein lipase $(2,3), b$ ) enhances neutrophil-mediated antibody dependent cytotoxicity (4), c) augments polymorphonuclear neutrophil phagocytosis (4) and, d) modulates the proliferation of numerous human and murine cell lines (5).

While it is known that macrophages and macrophage cell lines can elaborate TNF in response to endotoxin and other bacterial or protozoal products $(6)$,

**Abbreviations used in this paper:

TNF, tumor necrosis factor; LPS, lipopolysaccharide, CO, cyclooxygenase;

CFA, complete Freund's adjuvant. 
there is little information regarding factors that modulate TNF production. Considering the pleomorphic effects of TNF on various physiologic and immunologic activities, information regarding the modulation of TNF production may aid the understanding of both physiologic homeostatic and immune processes.

In this paper, we demonstrate that lipopolysaccharide (LPS) induced TNF production by activated murine macrophages is suppressed by low molar concentrations of exogenous prostaglandin $E_{2}$ ( $P G E_{2}$ ), while LPS-induced TNF production is augmented by the cyclooxygenase $(\mathrm{CO})$ inhibitor indomethacin. Furthermore, the production of TNF by immunologically activated macrophages is refractory to the phagocytic challenge zymosan ejther in the presence or absence of indomethacin. We provide evidence for a murine model of TNF production that demonstrates stimulus specificity and appears to be under the regulatory control of $\mathrm{PGE}_{2}$.

\section{MATERIALS AND METHODS}

Animals - Female, specific pathogen-free CBA/J mice (Jackson Laboratories, Bar Harbor, ME) were used in cell experiments. Mice were maintained under pathogen-free conditions and given food and water ad libitum.

Macrophage cultures - Resident peritoneal macrophages were recovered from normal mice by repeated washing of the peritoneal cavity ( $10 \times 1 \mathrm{ml}$ of RPMI1640 culture media). This macrophage population was washed $3 x$ and then suspended to $1 \times 10^{6} \mathrm{Mg} / \mathrm{m} 1$ RPMI with $5 \%$ fetal bovine serum (FBS) containing $100 \mathrm{U}$ penicillin and $100 \mu \mathrm{g}$ streptomycin/ml. One $\mathrm{ml}$ of suspension was placed onto 35 $\mathrm{mm}$ sterile plastic culture dishes. After $2 \mathrm{~h}$ incubation $\left(37^{\circ} \mathrm{C}, 5 \% \mathrm{CO}_{2}, 100 \%\right.$ humidity), non-adherent cells were removed by two vigorous rinses. Elicited peritoneal macrophages were recruited using either light mineral oil, thioglycollate, or complete Freunds adjuvant (CFA) as follows: $2 \mathrm{mls}$ of either Marcol-52 mineral oil or thioglycollate or $0.5 \mathrm{mls}$ of CFA (CFA diluted 1:1 with sterile saline) were asceptically administered via an intraperitoneal injection, four days post oil or thioglycollate or 14 days post CFA administration the macrophages were harvested by repeating washing of the peritoneal cavity, the cells were then washed and resuspended in complete culture media, and plated as described in the above methods for the resident macrophages.

After the initial $2 \mathrm{~h}$ adherence period, the monolayers were overlaid with 1 $\mathrm{ml}$ of serum-free media containing antibiotics plus the stimulus being tested for TNF induction, zymosan $(250 \mu \mathrm{g} / \mathrm{ml})$ or E. coli LPS (Sigma Chemical Co. , St. Louis, MO). Cell-free supernates were collected after 16h incubation. The total number of macrophages was quantitated by scraping the cells from the culture dishes and counting in a hemacytometer. All macrophage populations were $>95 \%$ mononuclear phagocytes as determined by staining, morphologic, and phagocytic indices.

Arachidonate metabolites and inhibitors - Prostaglandin $E_{2}$ was kindly provided by the Upjohn Co. (Kalamazoo, MI). Purity of the prostaglandins was confirmed by high pressure liquid chromatography as previously described (7). The in vitro specificity of indomethacin (Sigma Chemical Co.), as an inhibitor of products derived from the CO pathway, was assessed as previously published (8).

Radioimmunoassays for arachidonate metabolites - Cell-free culture medium from the various macrophage populations was subject to radioimmunoassay for 
PGE, (New England Nuclear, Boston, MA). Bound and free ligand were separated using dextran-coated charcoal. Sensitivity for PGE was 8 picograms.

Tumor necrosis factor assay - The activity of TNF was monitored using a semi-automated L929 fibrobjast lytic assay as previously described (9). Briefly, $L 929$ cells $\left(5 \times 10^{4} / 0.1 \mathrm{ml}\right)$ in the presence of $1 \mu \mathrm{g} / \mathrm{ml}$ actinomycin $D$ were cultured with serial 1:2 dilutions of test samples in 96-we11, flat bottom microtiter plates (Costar, Cambridge, MA) at $37^{\circ} \mathrm{C}, 5 \% \mathrm{CO} / 95 \%$ air humidified incubator. After $18 \mathrm{~h}$ incubation the plates were washed and the remaining cells stained with crystal violet $(0.5 \%)$ in methanol/water $(1: 4, \mathrm{~V} / \mathrm{V})$. The amount of cell lysis was determined using a micro ELISA autoreader. Units of TNF activity was defined as the reciprocal of the dilution necessary to lyse $50 \%$ of the L929 target cells. An internal standard of TNF was included in each assay; this material was a gift from Dr. Leo Lin; Cetus Corp., Emeryville, CA.

Statistical analysis - The Student's t-test was used to compare control and experimental groups. Values of $p>.05$ was considered not significant.

\section{RESULTS}

Production of TNF by various elicited and resident murine macrophage populations. Numerous studies have demonstrated that resting and elicited murine macrophage populations possess diverse morphologic and functional characteristics (10). This diversity is also reflected in the spectrum of inflammatory mediators produced by macrophages. As shown in figure 1, TNF

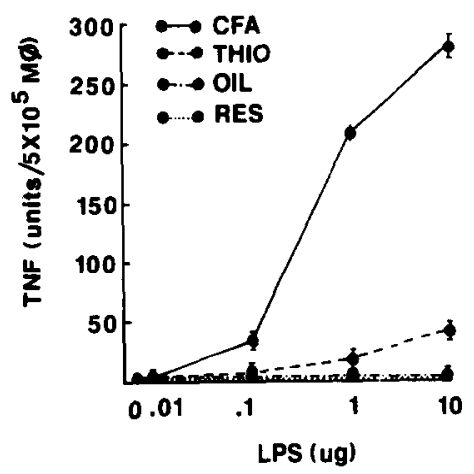

Figure 1. Production of tumor necrosis factor in response to graded doses of LPS. Only those Immunologically activated macrophages responded with a significant production of TNF in response to LPS. As a control, all TNF activity was destroyed by heating samples to $60^{\circ} \mathrm{C}$ for 30 min. CFA, complete Freund's adjuvant elicited; THIO, thioglycollate elfcited; OIL, ofl elicited, and RES, resident macrophages. Data represents mean \pm SEM of triplicates from three separate experiments. 
production varied dramatically depending upon both the concentration of the LPS stimulus and the macrophage population under study. Complete Freund's adjuvant (CFA) elfcited macrophages demonstrated augmented TNF production that was dependent upon the dose of LPS. TNF production by CFA elicited macrophages was first apparent between 10-100 $\mathrm{ng} / \mathrm{ml}$ LPS and increased in a linear fashion up to $10 \mu \mathrm{g} / \mathrm{ml}$. The only other macrophage population that demonstrated a significant capacity to produce TNF was thloglycollate elicited macrophages and then only when incubated with high levels of LPS $(10 \mu \mathrm{g} / \mathrm{ml})$. Resident and oil elicited peritoneal macrophages did not produce significant TNF even when incubated with $10 \mu \mathrm{g} / \mathrm{ml}$ LPS. While LPS proved to be a potent soluble stimulus for the production of TNF by CFA elicited macrophages, the phagocytic stimulus zymosan (250 $\mu \mathrm{g} / \mathrm{m} 1)$ did not induce the production of TNF by any of the resident or elicited macrophage populations. In addition, TNF activity was not found to be cell-assoctated in any of the above macrophage populations. Neither cytosolic nor membrane samples prepared by ultracentrifugation $(100,000 x g$ for 20 min) of freeze-thawed or sonicated macrophages demonstrated TNF activity.

\section{Effect of the cyclooxygenase inhibitor indomethacin on LPS-induced tumor}

necrosts factor production. Having defined CFA elicited macrophages as a significant cellular source of TNF, we utilized this macrophage population to study the potential regulatory effect of prostaglandins. Using the cyclooxygenase inhibitor, indomethacin, a dose dependent augmentation of TNF production was found which reached a maximum at $10^{-7} \mathrm{M}$ (Figure 2). At this concentration of indomethacin, LPS induced-TNF production was augmented 2-3 fold. Indomethacin had no augmenting effect on the production of TNF by zymosan treated CFA macrophages. Indomethacin alone had no effect on macrophage TNF production in the absence of LPS stimulation nor altered the viability of the $L 929$ cells at any of the concentrations under study. Figure 2 also shows the dose dependent suppression of LPS-induced PGE 2 production by indomethacin. An inverse relationship appears to exist between $P_{2}$ and $T N F$ production. Thus, this provided strong circumstantial evidence that $P_{G}$ suppressed TNF production. 

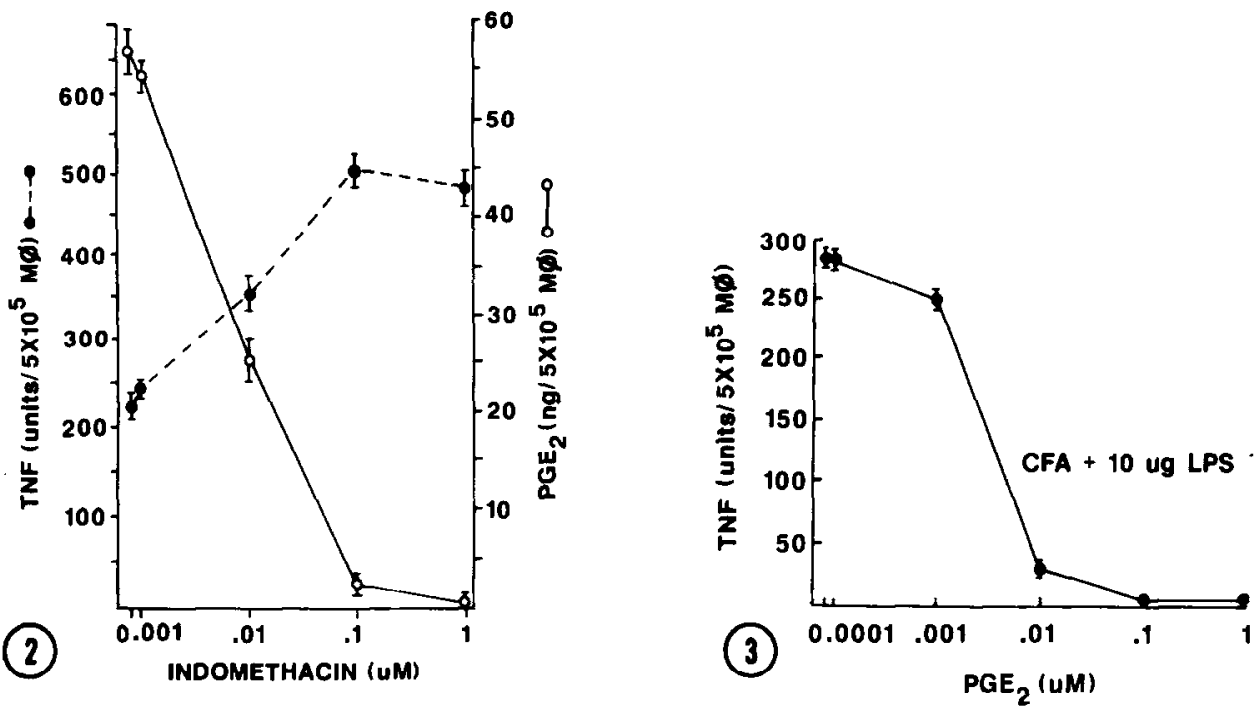

F1gure 2. Effect of the cyclooxygenase inhibitor indomethacin on LPS Induced TNF and $\mathrm{PGE}_{2}$ production by CFA elicited macrophages. Indomethacin Induced a dose dependent reduction in $P G E_{2}$ levels with a

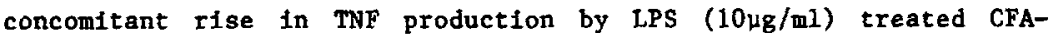
elicited macrophages. Indomethacin alone had no effect on the 1ytic assay. Data represents mean \pm SEM of triplicates from three separate experiments.

F1gure 3. Effect of exogenous PGE $_{2}$ on LPS $(10 \mu g / m 1)$-1nduced TNF production. Complete Freund's adjuvant-elicited macrophages were stimulated 16 hours with LPS in the presence of graded concentrations of $\mathrm{PGE}_{2}$, then supernates were tested for TNF activity. $\mathrm{PGE}_{2}$ alone had no effect on the lytic assay. Data represents mean \pm SEM of triplicates from three separate experiments.

Effect of exogenous PGE, on tumor necrosis factor production. The suppressive effect of $\mathrm{PGE}_{2}$ was confirmed by directly adding this agent to LPSstimulated CFA macrophages. As shown in Figure 3, exogenous PGE 2 caused a dose dependent suppression of TNF production. At $10^{-8} \mathrm{M}$, the production of TNF was reduced by approximately 90\%, while higher concentrations suppressed TNF production to basal levels. In control studies, $P G E_{2}$ alone had no effect on the viability of the $L 929$ cells. Thus, $P G E_{2}$ at low molar concentrations appears to directly suppress TNF production. 


\section{DISCUSSION}

Recent evidence suggests that TNF has a profound influence on cells that participate in various facets of the immune response. One of the major cellular sources for the production of TNF during an immune response appears to be macrophages; more specifically, those "activated" macrophages that have interacted with T-lymphocytes or their products and then triggered with a specific agonist $(6,11)$. In the present report we have utilized LPS treated, immunotogically elicited mouse peritoneal macrophages as a model to study the regulatory effects of $\mathrm{PGE}_{2}$ on TNF production. We provide evidence that $\mathrm{PGE}_{2}$ can down-regulate LPS-induced TNF production at near physiologic concentrations, while indomethacin, a potent inhibitor of $\mathrm{PGE}_{2}$ production, has a significant augmenting effect.

Our data imply that TNF production may be endogenously regulated by $\mathrm{PGE}_{2}$, potentially in a feedback type manner. This hypothesis is especially intriguing since LPS can serve as a stimulus for both TNF and PGE production by immunologically activated macrophage. Thus, CFA elicited macrophages when presented with an LPS challenge not only produce a biologically important mediator, TNF, but also produces a signal that may ultimately regulate mediator production. It is not clear as yet if TNF plays a role in the induction of $\mathrm{PGE}_{2}$ synthesis by macrophages, although a recent study has demonstrated that recombinant $T N F$ can stimulate $\mathrm{PGE}_{2}$ production by resting macrophages (12). The autoregulatory effect of $\mathrm{PGE}_{2}$ on TNF production is supported by the findings that gamma interferon which decreases PGE $_{2}$ production (13) augments lectininduced monocyte TNF production by 5-7 fold (14).

These data are in accord with recent studies from our laboratory demonstrating the ability of $\mathrm{PGE}_{2}$ to act in a classical feedback manner to regulate the production of the monokine interleukin-1 (15). In these studies, interleukin-1 demonstrated characteristics of a classical hormone by inducing the production of its own inhibitor.

In conclusion, we provide evidence that TNF production by LPS-stimulated, immunologically-activated macrophages is regulated by $\mathrm{PGE}_{2}$. These studies also 
lend additional support to the notion that $P G E_{2}$ is a major autokine determining macrophage responsiveness.

\section{ACKNOWLEDGEMENT}

This work was supported by NIH grants HL 31237 and HL 31963 . Dr. Kunkel is an established investigator of the American Heart Association. The authors wish to express their appreciation for the expert secretarial support of Kathleen Atkins.

\section{REFERENCES}

1. Carswe]1, E.A., 0]d, L.J., Kassel, R.I., Green, S. and Williamson, B. (1975). Proc. Nat1. Acad. Sci. USA 72, 3666-3679.

2. Beutler, B., Mahoney, J., Letrang, N., Pekala, P. and Cerami, A. (1985). J. Exp. Med. 161, 984-995.

3. Kawakami, M., Pekala, P.H., Lane, M.D. and Cerami, A. (1982). Proc. Natl. Acad. Sci. USA 79, 912-916.

4. Shalaby, M.R., Aggrawal, B.B., Rinderknecht, E., Svedersky, L.P., Finkle, B.S. and Palladino, M.A. (1985). J. Immunol. 135, 2069-2073.

5. Sugarman, B.J., Aggarwal, B.B., Hass, P.E., Figari, I.S., Palladino, M.A. and Shepard, H.M. (1985). Science 230, 943-945.

6. Ruff, M.R. and Gifford, G.E. (1981). Lymphokines 2, 235-271.

7. Fitzpatrick, F.A. and Bundy, G.L. (1978). Proc. Nat1. Acad. Sci. USA 75, 2689-2693.

8. Kunkel, S.L., Chensue, S.W., Mouton, C. and Higashi, G.I. (1984). J. Clin. Invest. 74, 514-524.

9. Aggarwal, B.B., Moffat, B., Lee, S.H. and Harkens, R. N. Thymic Hormones and Lymphokines, Goldstein, A. ed. pp. 235-249, Plenum Press, New York.

10. Adams, D.0. and Hamilton, T.A. (1984). Ann. Rev. Immunol. 2,283-318.

11. 01d, L.J. (1985) Science 230, 630-632.

12. Bachwich, P.R., Chensue, S.W., Larrick, J.W. and Kunkel, S.L. (1986). Biochem. Biophys. Res. Comm. (in press).

13. Boraschi, P. Censini, S. and Tagliabue, A. (1984). J. Immuno1. 133, 764-768.

14. Nedwin, G.E., Svedersky, L.P., Bringman, T.S., Palladino, M.A. and Goedde 1, D.V. (1985). J. Immuno1. 135, 2492-2497.

15. Kunke1, S.L., Chensue, S.W. and Phan, S.H. (1986). J. Immunol. 136 , 186-192. 